\title{
292
}

\section{Enumeration and Classification in Polysomic Inheritance}

\author{
Ronald A. Fisher \\ Division of Mathematical Statistics, \\ University of Adelaide, Southern Australia
}

(Received 8 fanuary 1962 )

When the structure of polysomic inheritance, characteristic of the forms often described as autopolyploid, was beginning to be understood, it soon appeared that the actual numbers of kinds of certain entities were so great as to present problems both of enumeration and of classification. For example, it was shown (Fisher, 1947) that in tetrasomic plants with $l$ marked loci in the same linkage group, the number of distinguishable modes of gamete formation could be calculated from the formula

$$
\frac{\mathrm{I}}{4^{8}}\left(\mathrm{I} 6^{l}+\mathrm{I} 6 \cdot 4^{l}+\mathrm{I} 6\right)
$$

yielding the series

$\begin{array}{lcccccc}\text { Number of loci } & \text { I } & 2 & 3 & 4 & 5 & 6 \\ \text { Number of modes } & 2 & \text { II } & \text { IO } 7 & \text { I45 I } & 22 \text { I } 87 & 35089 \text { I }\end{array}$

which may also be calculated as

where $a$ takes the values

$$
3 a^{2}-1
$$

$$
\begin{array}{llllll}
\text { I } & 2 & 6 & 22 & 86 & 342
\end{array}
$$

These modes differ in various ways, and may, therefore, be classified and the total number subdivided. One classification of concern to a geneticist is based on the number of loci, out of all available, at which double reduction has occurred, this being the only distinction between the two modes at a single locus. The same method of enumeration used above, based on a general combinatorial theorem, will serve to enumerate these sub-classes. In the expansion of

$$
(12 x+4 y)^{l}+3(4 x)^{l}+12(2 x+2 y)^{l}+(4 y)^{l}+16(y)^{l}
$$

the coefficient of $x^{l_{1}} y^{l_{2}}$ gives the number of modes in which double reduction does not take place at $l_{1}$ loci, but does take place at the remaining $l_{2}$. These are shown in Fig. 1 .

For example, with two loci there are only I I modes. Of these, two have 


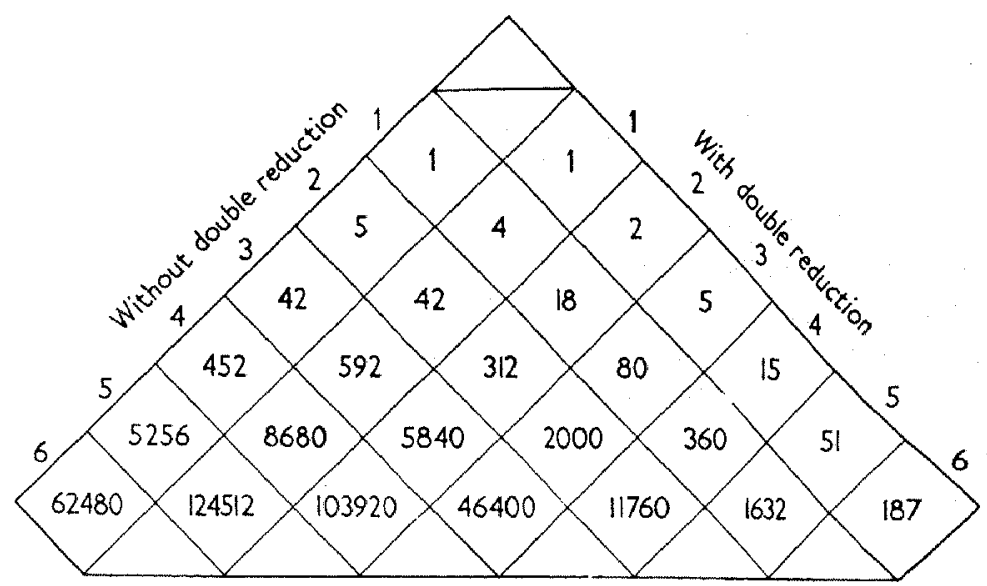

FIG. I. Modes of gamete formation divided according to the number showing double reduction.

double reduction at both loci; four at one; and five at neither. Those with unlike behaviour at the two loci necessarily form two conjugate pairs, generated by interchanging the two loci. The property of being one of a conjugate set is not enumerable by the general method used so far, but when recognized by an examination of the items, it is possible to make a two-way classification based both on double reduction and on symmetry. This is shown for the modes with two loci in Table $\mathbf{r}$.

TABLE I

Two loci

\begin{tabular}{cccc|c}
\hline Loci with double reduction & 0 & 1 & 2 & Total \\
\cline { 2 - 4 } Genera with one species & 5 & 0 & 2 & 7 \\
Genera with two species & 0 & 2 & 0 & 2 \\
Total genera & 5 & 2 & 2 & 9 \\
Total modes & 5 & 4 & 2 & I r \\
\hline
\end{tabular}

The modes for 3 loci have been set out in extenso (Fisher, 1947); from this list Table 2 has been constructed. This gives a much fuller classification.

The modes distinguishable with four loci number $\mathrm{r} 45 \mathrm{I}$, and I believe no full list has been published. I do not know any easy way of subdividing these by symmetry. Table 3 shows there are only 124 genera and that these are of six sizes, the largest of which have sets of 24 conjugates. 
Table 2

Three loci

\begin{tabular}{lrrrr|r}
\hline Loci with double reduction & 0 & 1 & 2 & 3 & Total \\
\cline { 2 - 6 } One species & 3 & 0 & 0 & 2 & 5 \\
Three species & 9 & 8 & 4 & 1 & 22 \\
Six species & 2 & 3 & 1 & 0 & 6 \\
\cline { 2 - 6 } Total genera & 14 & II & 5 & 3 & 33 \\
Total modes & 42 & 42 & 18 & 5 & 107 \\
\hline
\end{tabular}

TABLE 3

Four loci

\begin{tabular}{|c|c|c|c|c|c|c|}
\hline Loci with double reduction & $\circ$ & $\mathbf{I}$ & 2 & 3 & 4 & Total \\
\hline One species & $\mathbf{I}$ & $\circ$ & 0 & 0 & 2 & 3 \\
\hline Three species & 7 & 0 & o & 0 & $\mathbf{r}$ & 8 \\
\hline Four species & 4 & 4 & $\circ$ & 2 & $\mathbf{r}$ & I I \\
\hline Six species & 9 & $\circ$ & 12 & o & $\mathbf{r}$ & 22 \\
\hline Twelve species & 18 & 20 & $\mathrm{I} 2$ & 6 & $\circ$ & 56 \\
\hline Twenty-four species & 6 & 14 & 4 & o & 은 & 24 \\
\hline Total genera & 45 & 38 & 28 & 8 & 5 & 124 \\
\hline Total modes & 452 & 592 & 312 & 80 & 15 & $\mathrm{I}, 45 \mathrm{I}$ \\
\hline
\end{tabular}

\section{SUMMARY}

The available methods of enumeration facilitate a great many problems, but they do not supply all that might be useful. Further combinatorial problems deserve discussion. The modes of gamete formation supply only one of the several examples that could be given. Meanwhile, quite pedestrian methods can be used.

\section{REFERENCES}

Fisher, R. A. (1947). Phil. Trans. B, 233, 55-87.

Fisher, R. A. (1950). Proc. Roy. Soc. B, r36, 509-520. 